\title{
Heavy Oil Laminar Flow in Corrugated Ducts: A Numerical Study Using the Galerkin-Based Integral Method
}

\author{
Valdecir Alves dos Santos Júnior ${ }^{1, * \mathbb{C}}$, Severino Rodrigues de Farias Neto ${ }^{2}$, \\ Antonio Gilson Barbosa de Lima ${ }^{3}$, Igor Fernandes Gomes ${ }^{4}$, Israel Buriti Galvão ${ }^{5}$, \\ Célia Maria Rufino Franco ${ }^{6}$ and João Evangelista Franco do Carmo ${ }^{7}$ \\ 1 Department of Physics and Civil Engineering, Center of Science, Technology and Health, State University of \\ Paraíba, Cel. Pedro Targino Ave, 58233-000 Araruna-PB, Brazil \\ 2 Department of Chemical Engineering, Center of Science and Technology, Federal University of Campina \\ Grande, 882 Aprígio Veloso St, 58428-830 Campina Grande-PB, Brazil; severino.rodrigues@eq.ufcg.edu.br \\ 3 Department of Mechanical Engineering, Center of Science and Technology, Federal University of Campina \\ Grande, 882 Aprígio Veloso St, 58428-830 Campina Grande-PB, Brazil; antonio.gilson@ufcg.edu.br \\ 4 Department of Civil Engineering, Technology Center, Federal University of Pernambuco, Acadêmico Hélio \\ Ramos St, 50670-420 Recife-PE, Brazil; gomes@ufpe.br \\ 5 Department of Mathematics, Center of Science and Technology, State University of Paraíba, 351 Baraúnas St, \\ 58429-500 Campina Grande-PB, Brazil; galvao.mat@gmail.com \\ 6 Department of Physics and Mathematics, Federal University of Campina Grande, 58175-000 Cuité-PB, Brazil; \\ celiarufino@ufcg.edu.br \\ 7 Department of Mechanical Engineering, Federal University of Campina Grande, \\ 58429-900 Campina Grande-PB, Brazil; jevan.franco@gmail.com \\ * Correspondence: asjrvaldecir@gmail.com; Tel.: +55-83-99961-0088
}

Received: 20 February 2020; Accepted: 10 March 2020; Published: 15 March 2020

\begin{abstract}
Fluid flow in pipes plays an important role in different areas of academia and industry. Due to the importance of this kind of flow, several studies have involved circular cylindrical pipes. This paper aims to study fully developed internal laminar flow through a corrugated cylindrical duct, using the Galerkin-based integral method. As an application, we present a study using heavy oil with a relative density of $0.9648\left(14.6^{\circ} \mathrm{API}\right)$ and temperature-dependent viscosities ranging from 1715 to 13000 cP. Results for different fluid dynamics parameters, such as the Fanning friction factor, Reynolds number, shear stress, and pressure gradient, are presented and analyzed based on the corrugation number established for each section and aspect ratio of the pipe.
\end{abstract}

Keywords: fully developed flow; Galerkin-based integral (GBI) method; Poiseuille number; pressure gradient; petroleum

\section{Introduction}

The oil industry is a major player in the energy sector worldwide. The increased demand for light oil reserves in recent decades has led to their depletion. As a result, heavy oil is increasingly a topic of interest, receiving considerable attention regarding its efficient transportation. Although there is a large amount of productive crude oil reserves, heavy oil transportation is a complex and expensive task due to its high viscosity, which requires a large amount of energy to pump [1].

One of the major concerns in the production and transportation of heavy oil is related to load loss or pressure drops, which are associated with high flow costs. This occurs due to the fluid friction effect on the inner walls of the duct, making its transport difficult, and increasing the refining cost [2]. 
Currently, different methods are employed to transport heavy oil from the production field to refineries and markets. Although many other options are available, pipelines are the safest, most efficient, and financially viable means of transporting heavy oil [3].

For many years, analytical and numerical solutions applied to fluid flow inside ducts with arbitrary cross-sections have been studied. Aparecido and Cotta [4] applied generalized integral transform techniques to find solutions for forced laminar convection in rectangular ducts. The same authors, in 1991, presented a generalized integral transform technique for forced laminar convection solutions at the thermal entrance region of ducts with arbitrary cross-sections. Syrjala [5] performed a numerical study related to the laminar flow behavior of viscoelastic fluids in rectangular ducts using the finite element method. Aparecido and Lindquist [6] analytically studied a Newtonian fluid over laminar flow, developed hydrodynamically and thermally, by using generalized integral transformation techniques, with axial and uniform heat flow in straight rectangular ducts. Lee and Kuo [7] applied the Galerkin-based integral method to calculate the Nusselt number for laminar flow in elliptical ducts imposed on the constant duct wall temperature. Values for the coefficient of friction were also found for elliptical ducts with and without a central circular core.

How much to transport of heavy oils, several techniques are employed. These include heat addition, light oil dilution, emulsion formation, and lubrication of the pipe walls with a lower viscosity fluid, all with the aim to reduce the pressure drop along the duct. For transporting a $17.6 \mathrm{~Pa} \cdot \mathrm{s}$ viscosity oil with a density of $963 \mathrm{~kg} / \mathrm{m}^{3}$ at room temperature using the core-flow technique, Prada and Bannwart [8] found a reduction in the total pressure gradient between 45 and 150 times, compared to that obtained when the oil seeped alone into the pipe. Bensakhria et al. [9] experimentally evaluated the transport of heavy oil with a viscosity of $4.74 \mathrm{~Pa} \cdot \mathrm{s}$ at a constant temperature of $19.7^{\circ} \mathrm{C}$. The authors observed a reduction in pressure, with a drop of over $90 \%$ compared to that obtained with the same oil flowing without parietal lubrication, i.e., without applying the core-flow technique. These authors also observed that the difference in density between water and oil plays an important role in the flow behavior.

Thus, both numerical and experimental simulations are increasingly used to investigate in detail the local dynamics of fluid flow in pipelines, and in particular the importance of transporting heavy oil in this type of modal.

Given the real importance of this problem, in this paper, we propose to carry out a study on the fully developed laminar flow of heavy oil in corrugated cross-section ducts, presenting results for fluid dynamic parameters such as the Poiseuille number, Fanning friction factor, velocity, pressure gradient, shear stress, and Reynolds number, from the solution of the dimensionless momentum equation given by the Galerkin-based integral method, and considering temperature-dependent viscosity. When considering corrugated geometry, there are few works found in the literature. Among these few works, we can cite Casarella et al. [10], Hu and Chang [11], Moharana and Khandekar [12], and Shah [13]. Unfortunately, no work is applied to the petroleum industry.

The motivation for this research is related to the scarcity of work considering this geometry. Among these few works, we have the work of Hu and Chang [11] as a starting point. This work analyzes the fully developed flow over corrugated sine ducts. These authors employed the conformal mapping method and Green's functions to determine $f R e$ and $N u_{H 1}$. Different from the work of $\mathrm{Hu}$ and Chang, where the perimeter is calculated numerically, our work finds the perimeter by the arc length function. This function gives us an exact numeric value of the perimeter. Hu and Chang [11] also applied a perturbation method, the Galerkin internal variational method, and an integral contour equation method to analyze the same problem for corrugated ducts. They found that the perturbation method produced good results for minor disturbances. When the disturbance was large, the results were useful only for qualitative trends. In our research, we use serial approximations of the parameterization of the curve that represents the cross-section of the pipe, because such approximation results in computational gains. 
Further, the Galerkin-based integral method has been successfully applied in algorithms in the fields of differential equations [12-14], analysis [15], mechanics, thermodynamics and hydrodynamics [16-19], and also in other engineering fields [20,21]. Specifically, in the calculation of the temperature and/or velocity in ducts, we can cite works with circular, rectangular, isosceles triangular, right triangular, and annuli cross-sections [22-24].

\section{Mathematical Formulation}

In this work, we choose the cylindrical coordinate system $(r, \theta, z)$ for the mathematical formulation of the physical problem, and the following assumptions are considered:

(a) The laminar flow is fully developed, isothermal, single-phase, and steady-state;

(b) The cross-sectional area of the tube, along the z-axis, is constant;

(c) The properties of the fluid, thermal and physical, are considered constant;

(d) There is a condition of not-slipping on the duct wall.

\subsection{The Geometry}

The geometry to be analyzed is a corrugated cylindrical duct. For a duct with corrugated geometry we consider, in polar coordinates, the parameterization of the cross-section, $r(\theta)=a+b \sin (N \theta)$, where $a$ and $b$ are shown in Figure 1 and $N$ is the number of corrugations, sine-type. The relationship $\frac{a}{b}$ is the so-called aspect ratio,

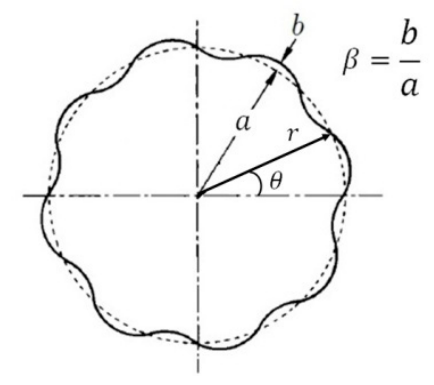

(a)

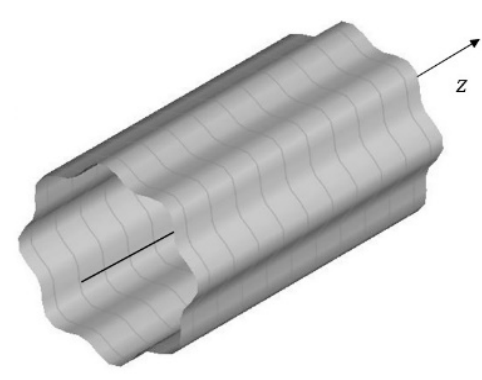

(b)

Figure 1. (a) Aspect ratio in a corrugated duct; (b) sine-type corrugated duct.

Thus, considering the cross-section of the duct with the parameterization as reported before, the cross-sectional area of the duct is given as follows:

$$
A_{c}=\frac{1}{2} \int_{0}^{2 \pi}[a+b \sin (N \theta)] d \theta
$$

For the perimeter of the cross-section of the duct, we use the definition of arc length as follows:

$$
P=\int_{0}^{2 \pi} \sqrt{[a+b \sin (N \theta)]^{2}+\left[\frac{d}{d \theta}[a+b \sin (N \theta)]\right]^{2}} d \theta
$$

\subsection{Momentum Equation}

The momentum equation for the domain and assumptions considered in a cylindrical coordinate system are given by:

$$
\frac{\partial^{2} u}{\partial r^{2}}+\frac{1}{r} \frac{\partial u}{\partial r}+\frac{1}{r^{2}} \frac{\partial^{2} u}{\partial \theta^{2}}=\frac{1}{\mu} \frac{d p}{d z}
$$


In the equation, $u(r, \theta)$ is the velocity component along the z-axis and annulled in the boundary, $\mu$ is the dynamic velocity of the fluid, and $\frac{d p}{d z}$ is the pressure gradient.

By considering the dimensionless variables

$$
R=\frac{r}{L}
$$

and

$$
W(R, \theta)=-\frac{u(R, \theta)}{\frac{L^{2}}{\mu} \frac{d p}{d z}}
$$

where $L=a$ is the characteristic length, we can write Equation (3) in the dimensionless form and apply it to the hydrodynamically fully developed flow as follows:

$$
\frac{\partial^{2} W}{\partial R^{2}}+\frac{1}{R} \frac{\partial W}{\partial R}+\frac{1}{R^{2}} \frac{\partial^{2} W}{\partial \theta^{2}}=1, W=0 \text { in } \Gamma
$$

The normalized dimensionless mean velocity of the fluid can be obtained as follows:

$$
U=\frac{u}{u_{m}}=\frac{W}{W_{m}}
$$

where $u_{m}$ and $W_{m}$ are the mean and dimensionless mean velocity, respectively.

\subsection{Solution Methodology}

In this work, we have employed the Galerkin-based integral (GBI) method on the MAPLE 17 platform for finding the numerical solution of Equation (6). The solution is approximated as a linear combination of a set of base functions. Thus, for Equation (6), we can write:

$$
W=\sum_{i=1}^{n} d_{i} f_{i}(R, \theta)
$$

The bases functions $f_{1}, f_{2}, \ldots, f_{n}$ are linearly independent functions and satisfy the same homogeneous boundary conditions of $W$. system:

Using Equation (8) and applying the GBI method in Equation (6), we obtain the following matrix

$$
A D=B
$$

with

$$
a_{i j}=\frac{1}{A_{c}} \int_{A_{c}}\left(\frac{\partial^{2} f_{i}}{\partial R^{2}}+\frac{1}{R} \frac{\partial f_{i}}{\partial R}+\frac{1}{R^{2}} \frac{\partial^{2} f_{i}}{\partial \theta^{2}}\right) f_{j} d A_{\mathcal{C}}
$$

and

$$
b_{i}=-\frac{1}{A_{c}} \int_{A_{c}} f_{i} d A_{c}
$$

The coefficients $d_{1}, d_{2}, \ldots, d_{n}$ can be determined as follows:

$$
D=A^{-1} B
$$

In this way, the mean velocity is given by:

$$
W_{m}=\frac{1}{A_{c}} \int_{A_{c}} W d A_{c}=\sum_{j=1}^{n} d_{j} \frac{1}{A_{c}} \int_{A_{c}} f_{j} d A_{c}=-\sum_{j=1}^{n} d_{j} b_{j}
$$


One of the flow parameters commonly used in practice is the Fanning friction factor, $f$, defined by:

$$
f=\frac{\tau_{w}}{\rho \frac{u_{m}^{2}}{2}}
$$

where $\tau_{w}=\frac{d_{h}}{4} \frac{d p}{d z}$ represents the shear stress and $d_{h}=\frac{4 A_{c}}{P}$ the hydraulic diameter.

The Reynolds number is defined as:

$$
\operatorname{Re}=\frac{\rho d_{h} u_{m}}{\mu}
$$

With these results, we can determine values for the Poiseuille number, which is defined as the product of the Reynolds number and the friction factor as follows:

$$
f R e=-\frac{D_{h}^{2}}{2 W_{m}}
$$

with $D_{h}=\frac{d_{h}}{L}$ as the dimensionless hydraulic diameter.

Considering the following parameterization in polar coordinates

$$
g(r, \theta)=a+b \sin (N \theta)-r, \text { with aspect ratio } \beta=\frac{b}{a}
$$

and the set of bases functions of the form,

$$
\left\{f_{i}\right\}=\left\{g(r, \theta), g(r, \theta) r^{2}, g(r, \theta) \theta^{2}, g(r, \theta) r^{2} \theta^{2}, \ldots, g(r, \theta) r^{n} \theta^{m}\right\}
$$

we can write the base functions as follows:

$$
f_{i}(r, \theta)=g(r, \theta) r^{n} \theta^{m} \text { with } n, m=0,2,4, \ldots, N
$$

where the subscript $i$ represents the i-th term of the set of base functions in Equation (18).

\subsection{Heavy Oil Flow Application}

The oil is classified as heavy with ${ }^{\circ} \mathrm{API}=14.6$, a relative density of $0.9648\left(20 / 4{ }^{\circ} \mathrm{C}\right)$, and the oil viscosity is reported in Table 1 . Thus, we have the value for the fluid density $\rho=952.17 \mathrm{~kg} / \mathrm{m}^{3}$. The cross-section of the duct does not change along the longitudinal direction ( $z$-axis), and we consider an oil mean velocity of $u_{m}=1 \mathrm{~m} / \mathrm{s}$.

Table 1. Values for temperature-dependent kinematic viscosity.

\begin{tabular}{cc}
\hline \multicolumn{2}{c}{ Oil } \\
\hline $\mathbf{T}^{\circ} \mathbf{C}$ & $\boldsymbol{v}(\mathrm{cS})$ \\
\hline 29.22 & 180.21 \\
51.16 & 70.786 \\
81.11 & 25.526 \\
108.5 & 11.840 \\
137.9 & 6.3270 \\
155.5 & 4.4980 \\
199.6 & 2.3870 \\
228.5 & 1.6520 \\
260.3 & 1.1560 \\
\hline
\end{tabular}




\section{Results and Discussion}

In this section, first, we present the numerical results for the Poiseuille number $f R e$ obtained for the different aspect ratio, $\beta$, and the number of corrugations, $N$, of the corrugated cross-section duct. The effect of the number of corrugations in the shape of the pipe can be observed in Figure 2.

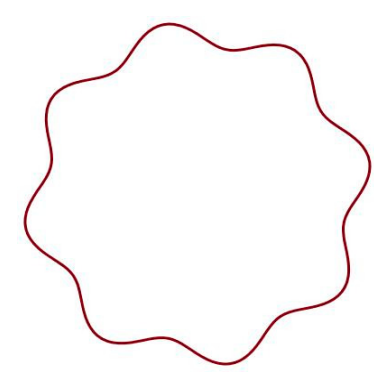

(a)

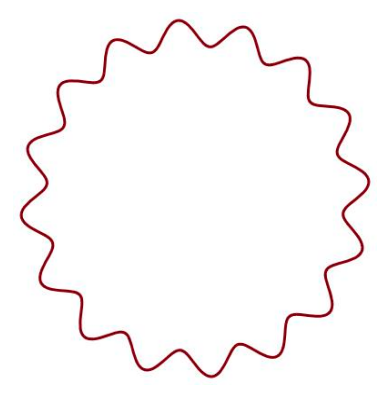

(c)

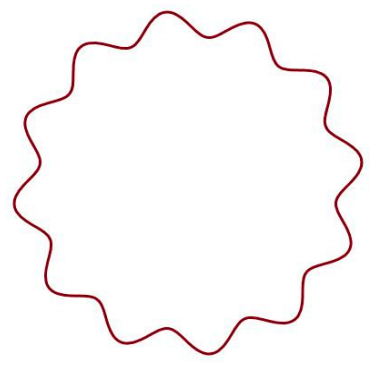

(b)

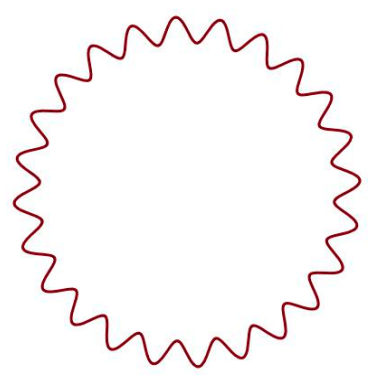

(d)

Figure 2. Cross sections of the duct for different numbers of corrugations: (a) $N=8$; (b) $N=12$; (c) $N=16 ;(\mathbf{d}) N=24$.

To obtain computational gains, a series approximation is performed for the function that represents the parameterization of the duct cross-section. For example, with $\frac{b}{a}=0.08$ and $N=12$, the following approximation can be used:

$$
\begin{aligned}
1+0.08 \sin (12 \theta) \cong 1+0.96 \theta+\quad & 0.4943780926 \times 10^{-4} \theta^{37}-0.4572997356 \times 10^{-3} \theta^{35} \\
& +0.3779074204 \times 10^{-2} \theta^{33}-0.2771321083 \times 10^{-1} \theta^{31} \\
& +0.1789811533 \theta^{29}-1.009254837 \theta^{27} \\
& +4.920117328 \theta^{25}-20.50048887 \theta^{23}+72.03644005 \theta^{21} \\
& -210.1062835 \theta^{19}+499.0024232 \theta^{17}-942.5601328 \theta^{15} \\
& +1374.566860 \theta^{13}-1489.114099 \theta^{11}+1137.517714 \theta^{9} \\
& -568.7588571 \theta^{7}+165.88-23.04 \theta^{3} \\
& +2.445874662 \times 10^{-9} \theta^{45}-1.629074706 \times 10^{-10} \theta^{47} \\
& -4.80367377 \times 10^{-6} \theta^{39}+4.217859899 \times 10^{-7} \theta^{41} \\
& -3.36307766 \times 10^{-8} \theta^{43}
\end{aligned}
$$

where $\theta$ is in radian.

However, no changes are made to the area values and perimeter of the duct. This approximation can be given at least in the first quadrant, because there is a periodicity in this type of geometry. The approximation reported in the series (Equation (20)) can be seen in Figure 3. 


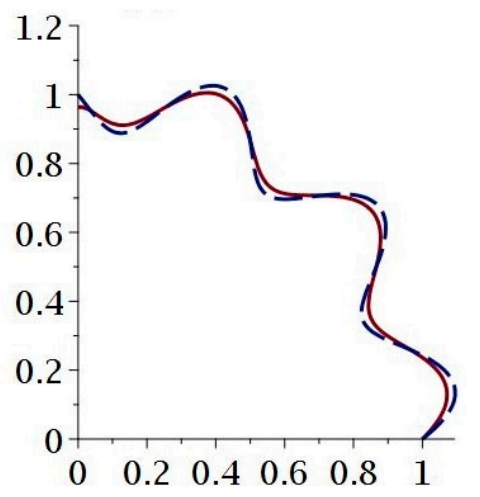

- $r(\theta)$ function (left side of Equation (20))

- A Approximation of $r(\theta)$ (right side of Equation (20))

Figure 3. Approximation in series of the function $r(\theta)$.

The $f R e$ values for different cases are presented in Table 2 and compared with the values reported in the literature [13]. Hu and Chang [11] employed the conformal mapping method and Green's functions. It is also important to note that unlike the literature, which uses numerical approximations for the perimeter value, in our work we use the arc length function. The good choice of the parameterization and the number of base functions created a good agreement between the predicted values for this research and the results reported in the literature. In some cases, the choice of the number of base functions from 3 to 52, as can be seen in Table 3, produces a significant increase in the computational time. The minimum computational time for some values was on average 1 minute, while the average maximum time was 2 hours and 15 minutes. Further, it is also observed that the numerical solution with the GBI method is in good agreement with the values reported in the literature. When the aspect ratio value tends to zero, this approximates the predicted Poiseuille number value for the values $f R e=$ 16 obtained for a circular cross-section pipe, validating the mathematical procedure used in this work.

The solution of Equation (7) makes it possible to find the dimensionless velocity distribution, as illustrated in Figure 4:

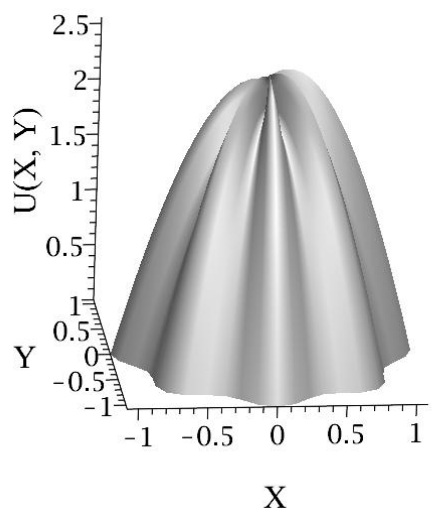

Figure 4. Dimensionless velocity profile (surface curve; $\beta=0.08$ and $N=8$ ).

Note that the graph in Figure 4 is plotted in Cartesian coordinates with $U(X, Y)$, where $X=\frac{x}{L}$ and $Y=\frac{y}{L}$. The values of the parameter $f$ Re for different numbers of corrugations are presented in Table 2 and in Figure 5, for better visualization of this parameter.

In the second part of the results, we present values for the Fanning friction factor, Reynolds number, shear stress, and pressure gradient in corrugated cross-sectional ducts with different aspect ratios changing from $\beta=0.02$ to 0.06 , and the number of corrugations $N=8,12,16$ and 24 . In Tables $4-11$, these results are shown. 
Table 2. Values for Poiseuille number, $(f R e)$, for a different number of corrugations.

\begin{tabular}{cccccccc}
\hline $\boldsymbol{N}$ & $\boldsymbol{\beta}$ & This Work & Ref [13] & $\boldsymbol{N}$ & $\boldsymbol{\beta}$ & This Work & Ref [13] \\
\hline 8 & 0.02 & 16.049 & 15.990 & 16 & 0.02 & 16.269 & 15.887 \\
& 0.04 & 16.046 & 15.962 & & 0.04 & 15.894 & 15.542 \\
& 0.06 & 15.918 & 15.915 & & 0.06 & 15.015 & 14.943 \\
& 0.08 & 15.858 & 15.850 & & 0.08 & 14.218 & 14.051 \\
& 0.10 & 15.741 & 15.765 & & & & \\
& 0.12 & 15.579 & 15.678 & & & & \\
12 & 0.02 & 16.029 & 15.952 & 24 & 0.02 & 16.043 & 15.679 \\
& 0.04 & 15.860 & 15.806 & & 0.04 & 14.868 & 14.671 \\
& 0.06 & 15.595 & 15.559 & & 0.06 & 12.839 & 12.872 \\
& 0.08 & 15.216 & 15.200 & & & & \\
& 0.10 & 14.541 & 14.711 & & & & \\
\hline
\end{tabular}

Table 3. Values for the number of base functions chosen for each aspect ratio $\beta$.

\begin{tabular}{cccccc}
\hline $\boldsymbol{N}$ & $\boldsymbol{\beta}$ & $\boldsymbol{n}$ & $\boldsymbol{N}$ & $\boldsymbol{\beta}$ & $\boldsymbol{n}$ \\
\hline 8 & 0.02 & 12 & 16 & 0.02 & 12 \\
& 0.04 & 13 & & 0.04 & 15 \\
& 0.06 & 11 & & 0.06 & 15 \\
& 0.08 & 7 & & 0.08 & 5 \\
& 0.10 & 5 & & & \\
& 0.12 & 5 & & & \\
12 & 0.02 & 30 & 24 & 0.02 & 15 \\
& 0.04 & 52 & & 0.04 & 15 \\
& 0.06 & 10 & & 0.06 & 6 \\
& 0.08 & 11 & & & \\
& 0.10 & 10 & & & \\
\hline
\end{tabular}

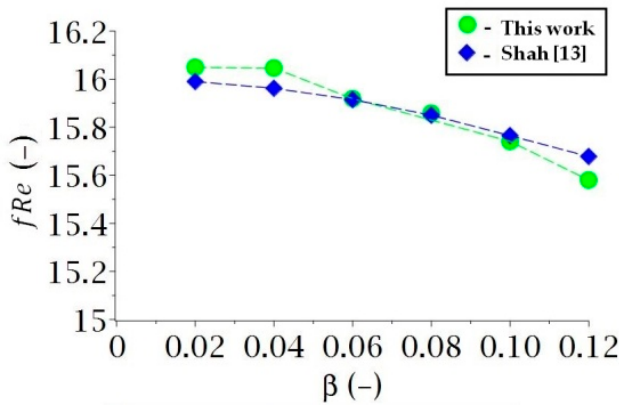

(a)

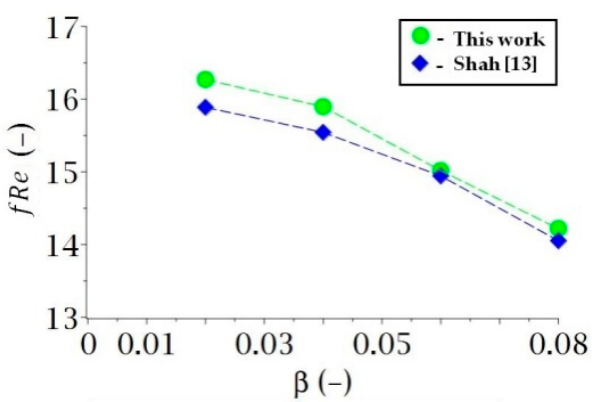

(c)

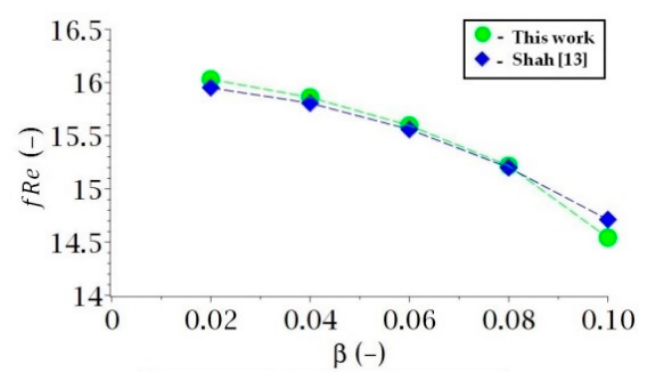

(b)

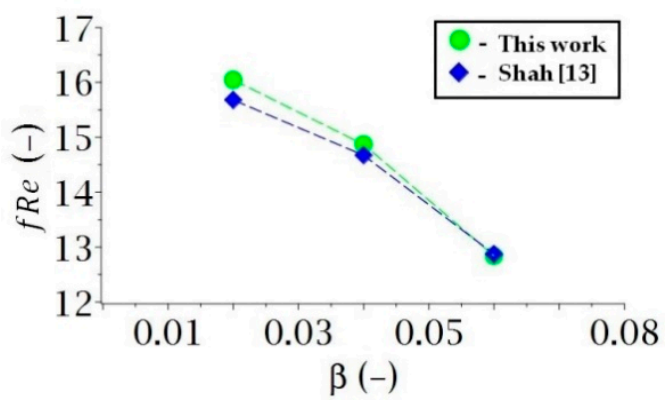

(d)

Figure 5. Data of $f$ Re for different aspect ratios $(\beta)$ of the pipe. (a) $N=8$; (b) $N=12$; (c) $N=16$; (d) $N=24$. 
Table 4. Values of the fluid dynamic parameter obtained in the simulations with $\beta=0.02$ and $N=8$.

\begin{tabular}{cccccc}
\hline $\begin{array}{c}\boldsymbol{T} \\
\left({ }^{\circ} \mathbf{C}\right)\end{array}$ & $\begin{array}{c}\mu \\
(\mathbf{P a} \cdot \mathbf{s})\end{array}$ & $\begin{array}{c}\boldsymbol{R e} \\
(-)\end{array}$ & $\begin{array}{c}f \\
(-)\end{array}$ & $\begin{array}{c}\bar{\tau}_{w} \\
\mathbf{( P a )}\end{array}$ & $\begin{array}{c}\frac{d p}{d z} \\
(\mathbf{P a} / \mathbf{m})\end{array}$ \\
\hline 29.22 & 171.60 & 11.0295 & 1.4413 & 686.20 & 1374.98 \\
51.17 & 67.400 & 28.0809 & 0.5661 & 269.52 & 540.061 \\
81.11 & 24.305 & 77.8710 & 0.2041 & 97.192 & 194.750 \\
108.5 & 11.273 & 167.883 & 0.0946 & 45.082 & 90.3333 \\
137.9 & 6.0244 & 314.167 & 0.0506 & 24.090 & 48.2718 \\
155.5 & 4.2828 & 441.915 & 0.0359 & 17.126 & 34.3175 \\
199.6 & 2.2728 & 832.734 & 0.0190 & 9.0887 & 18.2116 \\
228.5 & 1.5729 & 1203.23 & 0.0132 & 6.2901 & 12.6039 \\
260.3 & 1.1007 & 1719.49 & 0.0092 & 4.4015 & 8.81970 \\
\hline
\end{tabular}

Table 5. Values of the fluid dynamic parameters obtained in the simulations with $\beta=0.02$ and $N=12$.

\begin{tabular}{cccccc}
\hline $\begin{array}{c}\boldsymbol{T} \\
\left({ }^{\circ} \mathbf{C}\right)\end{array}$ & $\begin{array}{c}\mu \\
(\mathbf{P a} \cdot \mathbf{s})\end{array}$ & $\begin{array}{c}\boldsymbol{R e} \\
(-)\end{array}$ & $\begin{array}{c}f \\
\mathbf{( - )}\end{array}$ & $\begin{array}{c}\bar{\tau}_{w} \\
\mathbf{( P a )}\end{array}$ & $\begin{array}{c}\frac{d p}{d z} \\
(\mathbf{P a} / \mathbf{m})\end{array}$ \\
\hline 29.22 & 171.60 & 10.9438 & 1.4341 & 682.77 & 1404.52 \\
51.16 & 67.400 & 27.8627 & 0.5632 & 268.17 & 551.666 \\
81.11 & 24.305 & 77.2661 & 0.2031 & 96.707 & 198.935 \\
108.5 & 11.273 & 166.579 & 0.0942 & 44.856 & 92.2744 \\
137.9 & 6.0244 & 311.726 & 0.0503 & 23.970 & 49.3091 \\
155.5 & 4.2828 & 438.482 & 0.0357 & 17.041 & 35.0549 \\
199.6 & 2.2728 & 826.265 & 0.0189 & 9.0433 & 18.6029 \\
228.5 & 1.5729 & 1193.88 & 0.0131 & 6.2587 & 12.8747 \\
260.3 & 1.1007 & 1706.13 & 0.0091 & 4.3795 & 9.00922 \\
\hline
\end{tabular}

Table 6. Values of the fluid dynamic parameters obtained in the simulations with $\beta=0.02$ and $N=16$.

\begin{tabular}{cccccc}
\hline $\begin{array}{c}\boldsymbol{T} \\
\left({ }^{\circ} \mathbf{C}\right)\end{array}$ & $\begin{array}{c}\mu \\
(\mathbf{P a} \cdot \mathbf{s})\end{array}$ & $\begin{array}{c}\boldsymbol{R e} \\
(-)\end{array}$ & $\begin{array}{c}f \\
(-)\end{array}$ & $\begin{array}{c}\overline{\boldsymbol{\tau}}_{\boldsymbol{w}} \\
\mathbf{( P a )}\end{array}$ & $\begin{array}{c}\frac{d p}{d z} \\
(\mathbf{P a} / \mathbf{m})\end{array}$ \\
\hline 29.22 & 29.22 & 10.82772 & 1.4482 & 689.49 & 1423.29 \\
51.16 & 51.16 & 27.56704 & 0.5688 & 270.81 & 559.040 \\
81.11 & 81.11 & 76.44601 & 0.2051 & 97.658 & 201.594 \\
108.5 & 108.5 & 164.8108 & 0.0951 & 45.298 & 93.5076 \\
137.9 & 137.9 & 308.4180 & 0.0508 & 24.206 & 49.9681 \\
155.5 & 155.5 & 433.8285 & 0.0361 & 17.208 & 35.5234 \\
199.6 & 199.6 & 817.4951 & 0.0191 & 9.1323 & 18.8515 \\
228.5 & 228.5 & 1181.211 & 0.0132 & 6.3203 & 13.0468 \\
260.3 & 260.3 & 1688.028 & 0.0092 & 4.4226 & 9.12963 \\
\hline
\end{tabular}

Table 7. Values of the fluid dynamic parameters obtained in the simulations with $\beta=0.02$ and $N=24$.

\begin{tabular}{cccccc}
\hline $\begin{array}{c}\boldsymbol{T} \\
\left({ }^{\circ} \mathbf{C}\right)\end{array}$ & $\begin{array}{c}\mu \\
(\mathbf{P a} \cdot \mathbf{s})\end{array}$ & $\begin{array}{c}\boldsymbol{R} \boldsymbol{( - )} \\
\mathbf{( - )}\end{array}$ & $\begin{array}{c}f \\
\mathbf{( - )}\end{array}$ & $\begin{array}{c}\boldsymbol{\tau}_{w} \\
\mathbf{( P a )}\end{array}$ & $\begin{array}{c}\frac{d p}{d z} \\
(\mathbf{P a} / \mathbf{m})\end{array}$ \\
\hline 29.22 & 171.60 & 10.51788 & 1.4104 & 671.50 & 1454.98 \\
51.16 & 67.400 & 26.77820 & 0.5539 & 263.75 & 571.485 \\
81.11 & 24.305 & 74.25849 & 0.1997 & 95.110 & 206.082 \\
108.5 & 11.273 & 160.0947 & 0.0926 & 44.116 & 95.5893 \\
137.9 & 6.0244 & 299.5925 & 0.0495 & 23.574 & 51.0805 \\
155.5 & 4.2828 & 421.4144 & 0.0352 & 16.759 & 36.3142 \\
199.6 & 2.2728 & 794.1023 & 0.0186 & 8.8940 & 19.2712 \\
228.5 & 1.5729 & 1147.410 & 0.0129 & 6.1553 & 13.3372 \\
260.3 & 1.1007 & 1147.410 & 0.0090 & 4.3072 & 9.33287 \\
\hline
\end{tabular}


Table 8. Values of the fluid dynamic parameters obtained in the simulations with $\beta=0.06$ and $N=8$.

\begin{tabular}{cccccc}
\hline $\begin{array}{c}\boldsymbol{T} \\
\left({ }^{\circ} \mathbf{C}\right)\end{array}$ & $\begin{array}{c}\mu \\
(\mathbf{P a} \cdot \mathbf{s})\end{array}$ & $\begin{array}{c}\boldsymbol{R} \boldsymbol{( - )} \\
(29.22\end{array}$ & $\begin{array}{c}f \\
\mathbf{( - )}\end{array}$ & $\begin{array}{c}- \\
\mathbf{\tau _ { w }} \\
\mathbf{P a})\end{array}$ & $\begin{array}{c}\frac{d p}{d z} \\
(\mathbf{P a} / \mathbf{m})\end{array}$ \\
\hline 51.16 & 67.400 & 10.5343 & 1.3965 & 664.89 & 1391.80 \\
81.11 & 24.305 & 74.3745 & 0.1978 & 94.174 & 197.133 \\
108.5 & 11.273 & 160.344 & 0.0917 & 43.682 & 91.4386 \\
137.9 & 6.0244 & 300.060 & 0.0490 & 23.342 & 48.8625 \\
155.5 & 4.2828 & 422.072 & 0.0348 & 16.594 & 34.7374 \\
199.6 & 2.2728 & 795.342 & 0.0184 & 8.8065 & 18.4344 \\
228.5 & 1.5729 & 1149.20 & 0.0128 & 6.0948 & 12.7581 \\
260.3 & 1.1007 & 1642.28 & 0.0089 & 4.2649 & 8.92762 \\
\hline
\end{tabular}

Table 9. Values of the fluid dynamic parameters obtained in the simulations with $\beta=0.06$ and $N=12$.

\begin{tabular}{cccccc}
\hline $\begin{array}{c}\boldsymbol{T} \\
\left({ }^{\circ} \mathbf{C}\right)\end{array}$ & $\begin{array}{c}\mu \\
(\mathbf{P a} \cdot \mathbf{s})\end{array}$ & $\begin{array}{c}\boldsymbol{R e} \\
(-)\end{array}$ & $\begin{array}{c}f \\
\mathbf{( - )}\end{array}$ & $\begin{array}{c}\bar{\tau}_{w} \\
\mathbf{( P a )}\end{array}$ & $\begin{array}{c}\frac{d p}{d z} \\
(\mathbf{P a} / \mathbf{m})\end{array}$ \\
\hline 29.22 & 171.60 & 9.93330 & 1.3399 & 637.91 & 1480.35 \\
51.16 & 67.400 & 25.2898 & 0.5262 & 250.55 & 581.447 \\
81.11 & 24.305 & 70.1312 & 0.1897 & 90.353 & 209.674 \\
108.5 & 11.273 & 151.196 & 0.0880 & 41.909 & 97.2556 \\
137.9 & 6.0244 & 282.941 & 0.0470 & 22.395 & 51.9710 \\
155.5 & 4.2828 & 397.992 & 0.0334 & 15.921 & 36.9473 \\
199.6 & 2.2728 & 749.966 & 0.0177 & 8.4491 & 19.6072 \\
228.5 & 1.5729 & 1083.63 & 0.0122 & 5.8475 & 13.5697 \\
260.3 & 1.1007 & 1548.58 & 0.0085 & 4.0918 & 9.49557 \\
\hline
\end{tabular}

Table 10. Values of the fluid dynamic parameters obtained in the simulations with $\beta=0.06$ and $N=16$.

\begin{tabular}{cccccc}
\hline $\begin{array}{c}\boldsymbol{T} \\
\left({ }^{\circ} \mathbf{C}\right)\end{array}$ & $\begin{array}{c}\mu \\
(\mathbf{P a} \cdot \mathbf{s})\end{array}$ & $\begin{array}{c}\boldsymbol{R e} \\
(-)\end{array}$ & $\begin{array}{c}f \\
(-)\end{array}$ & $\begin{array}{c}\boldsymbol{\tau}_{\boldsymbol{w}} \\
\mathbf{( P a )}\end{array}$ & $\begin{array}{c}\frac{d p}{d z} \\
(\mathbf{P a} / \mathbf{m})\end{array}$ \\
\hline 29.22 & 171.60 & 9.25648 & 1.2723 & 605.76 & 1539.44 \\
51.16 & 67.400 & 23.5667 & 0.4997 & 237.92 & 604.658 \\
81.11 & 24.305 & 65.3527 & 0.1802 & 85.799 & 218.044 \\
108.5 & 11.273 & 140.894 & 0.0830 & 39.797 & 101.138 \\
137.9 & 6.0244 & 263.662 & 0.0440 & 21.266 & 54.0456 \\
155.5 & 4.2828 & 370.874 & 0.0310 & 15.118 & 38.4222 \\
199.6 & 2.2728 & 698.866 & 0.0168 & 8.0233 & 20.3899 \\
228.5 & 1.5729 & 1009.80 & 0.0116 & 5.5527 & 14.1114 \\
260.3 & 1.1007 & 1443.07 & 0.0081 & 3.8856 & 9.87463 \\
\hline
\end{tabular}

Table 11. Values of the fluid dynamic parameters obtained in the simulations with $\beta=0.06$ and $N=24$.

\begin{tabular}{cccccc}
\hline $\begin{array}{c}\boldsymbol{T} \\
\left({ }^{\circ} \mathbf{C}\right)\end{array}$ & $\begin{array}{c}\mu \\
(\mathbf{P a} \cdot \mathbf{s})\end{array}$ & $\begin{array}{c}\boldsymbol{R} \boldsymbol{( - )} \\
\mathbf{( - )}\end{array}$ & $\begin{array}{c}f \\
\mathbf{( - )}\end{array}$ & $\begin{array}{c}\boldsymbol{\tau}_{w} \\
\mathbf{( P a )}\end{array}$ & $\begin{array}{c}\frac{d p}{d z} \\
(\mathbf{P a} / \mathbf{m})\end{array}$ \\
\hline 29.22 & 171.60 & 7.92614 & 1.1217 & 534.036 & 1631.59 \\
51.16 & 67.400 & 20.1797 & 0.4405 & 209.757 & 640.854 \\
81.11 & 24.305 & 55.9603 & 0.1588 & 75.6402 & 231.097 \\
108.5 & 11.273 & 120.645 & 0.0736 & 35.0850 & 107.192 \\
137.9 & 6.0244 & 225.769 & 0.0393 & 18.7485 & 57.28089 \\
155.5 & 4.2828 & 317.572 & 0.0279 & 13.3287 & 40.7222 \\
199.6 & 2.2728 & 598.425 & 0.0148 & 7.07330 & 21.6104 \\
228.5 & 1.5729 & 864.674 & 0.0102 & 4.89530 & 14.9562 \\
260.3 & 1.1007 & 1235.67 & 0.0071 & 3.42553 & 10.4657 \\
\hline
\end{tabular}


When analyzing the results presented in Tables 4-11, it is observed that the flow of the considered oil has the following behavior: (a) the higher the temperature, the lower the oil viscosity, and (b) the higher the Reynolds number, the lower the friction factor, shear stress, and pressure gradient. The flow remains laminar in all variations of the pipe geometry. Also, when comparing values of the aspect ratio, for example, $\beta=0.02$ and 0.06 , and considering the same number of corrugations $N$, it was observed that the higher the aspect ratio, the greater the pressure gradient. Similarly, if we set a value for the aspect ratio, $\beta$, the pressure gradient increases as the number of corrugations $N$ increases. Such statements can be seen in Figure 6.

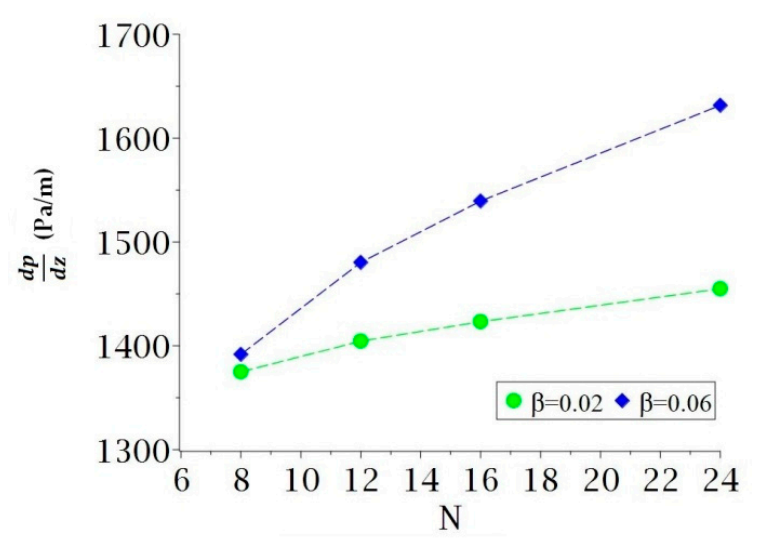

(a)

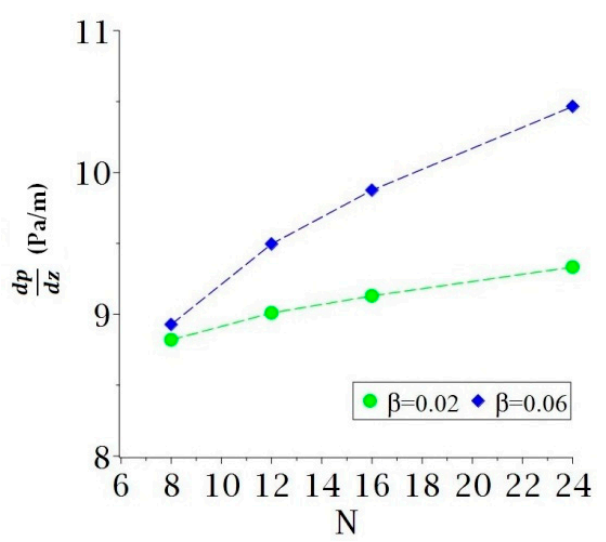

(b)

Figure 6. The pressure gradient is a function of the number of corrugations for different aspect ratios and fluid temperatures: (a) $\mathrm{T}=29.22^{\circ} \mathrm{C}$; (b) $\mathrm{T}=260.3^{\circ} \mathrm{C}$.

\section{Conclusions}

From the obtained results, the following conclusions can be cited:

1. The Galerkin-based integral method assisted by symbolic manipulation software is an effective tool for investigating the fully developed laminar flow fluid in a corrugated cross-section cylindrical duct. Fully developed velocity profiles for any duct shape can be predicted by this method.

2. The Poiseuille number, $f R e$, obtained for different aspect ratios of the pipe was compared with the existing literature, and a good concordance was obtained in all studied cases.

3. The appropriate number of base functions is different depending on the aspect ratio and the number of corrugations of the studied geometry. Such variation altered the computational time significantly. The smaller the number of base functions, the lower the computational time.

4. The pressure gradient increases with the number of corrugations and the aspect ratio of the pipe and decreases with the increase in the fluid temperature.

5. Values for the Reynolds number, Fanning friction factor, shear stress, and pressure gradient for heavy oil flow, with temperature-dependent viscosity, were presented. These results make it possible to better understand the behavior of heavy oil in corrugated cross-section ducts.

Author Contributions: Conceptualization, software, and formal analysis, V.A.d.S.J. and S.R.d.F.N.; writing一original draft preparation and editing, V.A.d.S.J.; supervision, review and resources, S.R.d.F.N. and A.G.B.d.L.; validation, formal analysis, review and funding acquisition, I.B.G., I.F.G., C.M.R.F. and J.E.F.d.C. All authors have read and agreed to the published version of the manuscript.

Acknowledgments: The authors thank CNPq, Finep, and Capes (Brazilian Research Agencies) for the financial support, and the authors of the cited references who helped in the improvement.

Conflicts of Interest: The authors declare no conflict of interest. 


\section{List of Symbols}

\begin{tabular}{ll}
$a, b$ & Geometric dimensions (m) \\
$a_{i j}$ & Element of matrix $A$ \\
$A_{c}$ & Cross-section area of the duct $\left(\mathrm{m}^{2}\right)$ \\
$A^{-1}$ & Inverse matrix of $A$ \\
$A, B, D$ & Matrix \\
$b_{j}$ & Element of matrix $B$ (constants) \\
$d_{h}$ & Hydraulic diameter (m) \\
$d_{j}$ & Constants to be evaluated (constants) \\
$D_{h}$ & Dimensionless hydraulic diameter \\
$f$ & Fanning friction factor (dimensionless) \\
$f_{i}$ & Base functions; Galerkin functions \\
$f R e$ & Poiseuille number (dimensionless) \\
$L$ & Characteristic length (m) \\
$n$ & Number of base functions \\
$N u_{H 1}$ & Nusselt number for the constant flux boundary condition \\
$P$ & Perimeter (m) \\
$p$ & Pressure (Pa) \\
$r, \theta, z$ & Cylindrical coordinates \\
$R e$ & Reynolds number [dimensionless] \\
$u$ & Local axial velocity (m/s) \\
$T$ & Temperature ( $\left.{ }^{\circ} \mathrm{C}\right)$ \\
$u_{m}$ & Mean velocity (m/s) \\
$U$ & Normalized velocity (dimensionless) \\
$x, y, z$ & Cartesian coordinates (m/s) \\
$X, Y, Z$ & Dimensionless coordinates (dimensionless) \\
$W$ & Dimensionless velocity (dimensionless) \\
$W_{m}$ & Dimensionless mean velocity (dimensionless) \\
$\beta$ & Aspect ratio (dimensionless) \\
$\mu$ & Dynamic viscosity (Pa·s) \\
$v$ & Kinematic viscosity (cS) \\
$\rho$ & Density (kg/m ${ }^{3}$ ) \\
$\tau_{w}$ & Shear stress (Pa) \\
$\Gamma$ & Boundary of duct \\
& Laplacian operator \\
\hline &
\end{tabular}

\section{Abbreviations}

GBI Galerkin-based integral

\section{References}

1. Jadidi, A.; Saleh, S.J. Lubricated Transport of Heavy Oil Investigated by CFD. Ph.D. Thesis, Department of Engineering, University of Leicester, Leicester, UK, 2017.

2. Andrade, T.H.F.; Damacena, Y.T.; Crivelaro, K.C.O.; Farias Neto, S.R.; Lima, A.G.B. Friction Reduction in Two-Phase Water-Oil Flow in Horizontal Tubes, XV Brazilian Congress of Mechanical Engineering; Águas de Lindóia: São Paulo, Brazil, 2010. (In Portuguese)

3. Moharana, M.K.; Khandekar, S. Generalized formulation for estimating pressure drop in fully developed laminar flow in singly and doubly connected channels of non-circular cross-sections. Comput. Methods Appl. Mech. Eng. 2013, 259, 64-76. [CrossRef]

4. Aparecido, J.B.; Cotta, R.M. Thermally developing laminar flow inside rectangular ducts. Int. J. Heat Mass Transf. 1990, 33, 341-347. [CrossRef]

5. Syrjälä, S. Laminar flow of viscoelastic fluids in rectangular ducts with heat transfer: A finite element analysis. Int. Commun. Heat Mass Transf. 1998, 25, 191-204. [CrossRef] 
6. Aparecido, J.B.; Lindquist, C. Laminar Forced Convection through Rectangular Ducts with Uniform Axial and Peripheral Heat Flux; Brazilian Congress of Mechanical Engineering: Águas de Lindóia, Brazil, 1999.

7. Lee, Y.M.; Kuo, Y.M. Laminar flow in annuli ducts with constant wall temperature. Int. Commun. Heat Mass Transf. 1998, 25, 227-236. [CrossRef]

8. Venegas Prada, J.W. Experimental Study of Annular Oil-Water Flow (Core Flow) in the Elevation of Ultra-Hazardous Oils. Master's Thesis, Petroleum Sciences, and Engineering, State University of Campinas, Campinas, Brazil, 1999. (In Portuguese).

9. Bensakhria, A.; Peysson, Y.; Antonini, G. Experimental study of the pipeline lubrication for heavy oil transport. Oil Gas Sci. Technol. 2004, 59, 523-533. [CrossRef]

10. Casarella, M.J.; Laura, P.A.; Chi, M. On the approximate solution of flow and heat transfer through non-circular conduits with uniform wall temperature. Br. J. Appl. Phys. 1967, 18, 1327. [CrossRef]

11. Hu, M.H.; Chang, Y.P. Optimization of finned tubes for heat transfer in laminar flow. J. Heat Transf. 1973, 95, 332-338. [CrossRef]

12. Shah, R.K. Laminar flow friction and forced convection heat transfer in ducts of arbitrary geometry. Int. J. Heat Mass Transf. 1975, 18, 849-862. [CrossRef]

13. Courant, R.; David, H. Methods of Mathematical Physics: Partial Differential Equations; John Wiley \& Sons: New York, NY, USA, 2008.

14. Petrovsky, I.G. Lectures on Partial Differential Equations; Dover Publications: New York, NY, USA, 1991.

15. Browder, F.E. Problemes Non-Lineaires; Presses de l'Université de Montréal: Montréal, QC, Canada, 1966; Volume 15.

16. Dautray, R.; Lions, J.L. Mathematical Analysis and Numerical Methods for Science and Technology; Evolution Problems II; Springer Science \& Business Media: Berlin/Heidelberg, Germany, 2012; Volume 6.

17. Assan, A.E. Finite Elements Methods-First Steps; Unicamp: Campinas, Brazil, 2003.

18. Cooper, J.M. Introduction to Partial Differential Equations with MATLAB; Springer Science \& Business Media: Berlin/Heidelberg, Germany, 2012.

19. Thomas, J.E. Fundamentals of Petroleum Engineering, 2nd ed.; Interciência, Petrobras: Rio de Janeiro, Brazil, 2004. (In Portuguese)

20. Franco, C.M.R.; Barbosa de Lima, A.G.; Silva, J.V.; Nunes, A.G. Applying liquid diffusion model for continuous drying of rough rice in fixed bed. Defect Diffus. Forum 2016, 369, 152-156. [CrossRef]

21. Santos, J.P.S.; Santos, I.B.; Pereira, E.M.A.; Silva, J.V.; de Lima, A.G.B. Wheat convective drying: An analytical investigation via galerkin-based integral method. Defect Diffus. Forum 2015, 365, 82-87. [CrossRef]

22. Haji-Sheikh, A.; Mashena, M.; Haji-Sheikh, M.J. Heat transfer coefficient in ducts with constant wall temperature. J. Heat Transf. 1983, 105, 878-883. [CrossRef]

23. Lakshminarayanan, R.; Haji-Sheikh, A. Entrance heat transfer in isosceles and right triangular ducts. J. Thermophys. Heat Transf. 1992, 6, 167-171. [CrossRef]

24. Lee, Y.M.; Lee, P.C. Laminar flow in elliptic ducts with and without central circular cores for constant wall temperature. Int. Commun. Heat Mass Transf. 2001, 28, 1115-1124. [CrossRef]

(C) 2020 by the authors. Licensee MDPI, Basel, Switzerland. This article is an open access article distributed under the terms and conditions of the Creative Commons Attribution (CC BY) license (http://creativecommons.org/licenses/by/4.0/). 